\title{
Changes in Seizure Frequency and Test-Retest Scores on the Wechsler Adult Intelligence Scale
}

\author{
${ }^{*}$ Michael Seidenberg, $†$ Daniel S. O'Leary, ${ }^{* *}$ Stanley Berent, and \\ $\dagger$ Thomas Boll \\ *Regional Institute for Children and Adolescents, Rockville, Maryland; \\ †Psychology Department, University of Health Sciences/The Chicago Medical \\ School, Chicago, Illinois; and ${ }^{* *}$ Ann Arbor Veterans Administration \\ Medical Center, and the University of Michigan. \\ Ann Arbor, Michigan
}

\begin{abstract}
Summary: Test-retest performance on the Wechsler Adult Intelligence Scale (WAIS) of two groups of adult epilepsy patients are presented and compared. In one group, Seizures Improved (SI) group, seizure frequency had decreased during the test-retest interval, and in the other group, Seizures Unimproved (SU) group, the number of seizures had either increased or stayed the same over the test-retest interval. The SI group showed a significant test-retest improvement on WAIS Verbal IQ, Performance IQ, and Full Scale IQ, as well as on eight of 11 WAIS subtests. In comparison, the SU group showed significant increases only on the Performance IQ and Object Assembly subtest. Furthermore, differences between the two groups were observed in the pattern of test-retest changes seen on the Performance measures relative to the Verbal measures. The results suggest that change in seizure frequency is one of the factors associated with test-retest changes in the intellectual functioning of epilepsy patients.
\end{abstract}

Intellectual changes resulting from seizures were one of the first issues to receive considerable attention in the epilepsy literature. Initially, there was a persistent belief that intellectual deterioration was an assured outcome of recurrent seizures. Several investigators, beginning with Paskind (1932), pointed out that the assumption of intellectual deterioration was based upon observation of institutionalized epilepsy patients and, therefore, constituted a very selective and unrepresentative sample. Review articles by Folsom (1953) and Tarter
(1972) showed that when noninstitutionalized epilepsy patients were studied, the degree of intellectual deficits and deterioration reported by early investigators was found to be greatly diminished.

The most direct means of assessing intellectual changes over a period of time is through test-retest procedures. Reports of such longitudinal studies in the field of epilepsy over the past 20 to 25 years are quite scarce. As already indicated, several of the earlier studies that did employ testretest paradigms used institutionalized

Received May 12, 1980; revision received September 17, 1980.

Address correspondence and reprint requests to Dr. Seidenberg at Regional Institute for Children and Adolescents, 15000 Broschart Road, Rockville, Maryland 20850.

Key words: Test-retest-Seizure frequency-Seizures improved-Seizures unimproved. 
epilepsy patients (Fox, 1924; Patterson and Fonner, 1928; Collins, 1941). Nevertheless, the results of these studies, as well as a few using noninstitutionalized patients, failed to support a strict intellectual deterioration hypothesis. While findings did indicate considerable variability in retest scores on standardized psychometric tests of intellectual functioning, instances of stability and performance increases occurred as often as did decreases (Dawson and Conn, 1929; Fetterman and Barnes, 1934; Sullivan and Gahagan, 1935; Tenny, 1955).

A few studies have reported variables that may be related to whether performance increases or decreases are observed. For example, Arieff and Yacorzynski (1942; see also Yacorzynski and Arieff, 1942) found that the test-retest losses in intellectual performance were significantly greater in a group with a known etiology for their seizures when compared with a group whose seizure etiology was unknown. Attempts to correlate other clinical variables, such as seizure frequency or severity, with the direction of test-retest changes have yielded mixed results. There have been reports of no relationship (Fox, 1924; Patterson and Fonner, 1928; Arieff and Yacorzynski, 1942), as well as reports that improvements in test scores were related to improvement in clinical status (Chaudhry and Pond, 1961; Rodin, 1968). However, differences between these various studies in basic features, such as sample selection (institutionalized versus noninstitutionalized), age of the sample studied (children or adults), and the type of tests administered, make it difficult to interpret these findings.

A sample of adult epilepsy patients is examined in the present study with regard to test-retest changes in the level of intellectual functioning. Intellectual functioning is assessed by the Wechsler Adult Intelligence Scale (WAIS), currently one of the most widely used clinical instruments for such an assessment. The study will examine the relationship between changes over time in seizure frequency (improvement versus no improvement), and test-retest scores on the WAIS.

\section{METHODS}

\section{Subjects}

From the patient pool of the Epilepsy Center at the University of Virginia Hospital, all patients 16 years of age and older who had been seen twice for evaluation of intellectual functioning were included for consideration in the present study. The recall of patients for reevaluation was not based on clinical information or evident changes in clinical status. However, the following were considered in the decision to invite patients for a second testing session: patient responsiveness to other Epilepsy Center contacts, distance from the Center, and date of initial testing. There is no reason to believe that the selection process used differentially affected the two experimental groups (SI and SU). The medical charts of these patients were reviewed to evaluate the number of seizures that had occurred prior to the first testing and in the interval between testings. Based on this seizure frequency information, the patients were divided into two groups: the Seizures Improved (SI) group, and the Seizures Unimproved (SU) group. A person was placed in the SI group if he had fewer seizures in the interval between testings than had occurred for an equivalent period of time prior to the first testing. If the number of seizures that occurred during the testretest interval was the same or higher than it was prior to the first testing, the patient was placed in the SU group. According to these criteria, 22 patients showed seizure improvement (12 males and 10 females), and 25 patients showed no improvement in their seizures (12 males and 13 females). Seven patients were found to be seizurefree for both intervals of time and were dropped from further consideration. Table 1 provides descriptive neurologic and demographic information for the two groups.

No significant differences were revealed by $t$-tests between the two groups for age of 
TABLE 1. Descriptive information for Seizures Improved (SI) group and Seizures Unimproved $(S U)$ group

\begin{tabular}{|c|c|c|}
\hline Descriptive information & SI Group $(N=22)$ & SU Group $(N=25)$ \\
\hline \multicolumn{3}{|l|}{ Age $^{\prime \prime}$} \\
\hline $\bar{x}$ & 22.3 & 21.8 \\
\hline SD & 6.1 & 6.3 \\
\hline \multicolumn{3}{|l|}{ Education ${ }^{b}$} \\
\hline $\bar{x}$ & 10.9 & 10.5 \\
\hline SD & 4.8 & 2.1 \\
\hline \multicolumn{3}{|l|}{ SES } \\
\hline $\bar{x}$ & 54.3 & 56.7 \\
\hline SD & 13.3 & 17.1 \\
\hline \multicolumn{3}{|l|}{ Retest Interval" } \\
\hline $\bar{x}$ & 18.6 & 19.4 \\
\hline SD & 7.3 & 6.6 \\
\hline \multicolumn{3}{|l|}{ Onset" } \\
\hline $\bar{x}$ & 8.6 & 10.0 \\
\hline SD & 6.4 & 4.6 \\
\hline \multicolumn{3}{|l|}{ Primary Seizure Diagnosis" } \\
\hline Partial elementary & 2 & 3 \\
\hline Partial complex & 5 & 9 \\
\hline Partial secondarily generalized & 2 & 3 \\
\hline Absence & 6 & 4 \\
\hline Tonic-clonic & 7 & 6 \\
\hline \multicolumn{3}{|l|}{ Average Monthly Seizures } \\
\hline \multicolumn{3}{|l|}{ Initial testing } \\
\hline - $\quad<1$ seizure & 5 & 7 \\
\hline $1-4$ seizures & 4 & 8 \\
\hline $5-10$ seizures & 3 & 1 \\
\hline$>10$ seizures & 10 & 9 \\
\hline \multicolumn{3}{|l|}{ Retest } \\
\hline$<1$ seizure & 14 & 5 \\
\hline $1-4$ seizures & 4 & 5 \\
\hline $5-10$ seizures & 1 & 4 \\
\hline$>10$ seizures & 3 & 11 \\
\hline
\end{tabular}

"Age and onset in years.

bducational values reflect highest grade completed.

"SES: Social-economic status; higher scores indicate lower SES (Myers and Bean, 1968).

"Retest interval in months.

" Seizure type is classified by the International Classification (Gastaut, 1970).

patients at time of testing, length of retest interval, age at seizure onset, education, or socioeconomic status. The mean age of SI patients at first testing was 22 years, 3 months, and for the SU group it was 21 years, 8 months. The retest interval was 18.6 months for the SI group, and 19.4 months for the SU group. As can be seen from the breakdown in Table 1 , there was a similar distribution of seizure diagnosis for the patients in the two groups. In the SI group, the primary seizure diagnosis of the patients included seven with tonic-clonic seizures, six with absence seizures, five with partial complex seizures, two with partial elementary seizures, and two with partial secondarily generalized seizures. Twelve patients also had a secondary seizure diagnosis, including three with absence seizures, six with tonic-clonic seizures, and three with partial secondarily generalized seizures. The primary seizure diagnosis of the patients in the SU group included four with absence seizures, six with tonic-clonic seizures, nine with partial complex seizures, three with partial elementary, and three with partial secondarily generalized seizures. Ten of the patients had a second seizure type, including four with tonic-clonic seizures, three with partial secondarily gen- 
eralized seizures, one patient with absence, one with partial elementary, and one with partial complex seizures. It can also be seen from Table 1 that the distribution of average monthly seizure frequency was similar for the two groups at initial testing, but as would be expected, it was quite different at retest.

\section{Wechsler Scales}

Test-retest comparisons are provided for the two groups on the WAIS. Data comparing the three summary IQ scores [Verbal IQ (VIQ), Performance IQ (PIQ), and Full Scale IQ (FSIQ)], and the 11 subtest scales that comprise the VIQ and PIQ measures [Information (Info), Comprehension (Comp), Similarities (Sim), Arithmetic (Arith), Vocabulary (Voc), Digit Span (DS), Picture Completion (PC), Picture Arrangement (PA), Block Design (BD), Object Assembly (OA), and Digit Symbol (Sym)] are provided.

\section{RESULTS}

To compare WAIS test-retest scores of the two groups, two separate, repeated measures analyses of variance were employed. The first compared the SI and SU groups at test time (1) to retest time (2) for the three summary WAIS IQ scores (VIQ, PIQ, and FSIQ). This yielded a $2 \times 2$ $\times 3$ analysis (Group $\times$ Time $\times$ Task). A second repeated measures analysis of variance was performed on the 11 WAIS subtest scores yielding a $2 \times 2 \times 11$ analysis (Group $\times$ Time $\times$ Task). Following the overall analyses, the individual test-retest means for each WAIS measure were compared using an extension of Duncan's New Multiple Range Test (Kramer, 1956). The results for the two analyses of variance are presented in Table 2.

In both analyses, important differences between the SI and SU groups, as well as differences in the pattern of test-retest performance, are revealed by the significant interactions between Time $\times$ Group and
TABLE 2. Results of analyses of variance

\begin{tabular}{|c|c|c|c|}
\hline Variable & $F$ value & $\begin{array}{l}\text { Degrees of } \\
\text { freedom }\end{array}$ & Probability \\
\hline \multicolumn{4}{|c|}{ Analysis: Group $\times$ Time $\times$ IQ summary scores $(2 \times 2 \times 3$} \\
\hline \multicolumn{4}{|c|}{ Main effects } \\
\hline Group & 1.63 & 1 & ns \\
\hline Time & 23.60 & 1 & 0.001 \\
\hline Task & 4.64 & 2 & 0.01 \\
\hline \multicolumn{4}{|c|}{ Interactions } \\
\hline \multicolumn{4}{|c|}{ Group $x$} \\
\hline Time & 9.87 & 1 & 0.01 \\
\hline \multicolumn{4}{|l|}{ Task $\times$} \\
\hline Time & 18.32 & 2 & 0.001 \\
\hline \multicolumn{4}{|c|}{ Group $\times$} \\
\hline Task & 0.16 & 2 & ns \\
\hline \multicolumn{3}{|c|}{ Group $\times$} & Time $\times$ \\
\hline Task & 0.22 & 2 & ns \\
\hline \multicolumn{4}{|c|}{ Analysis: Group } \\
\hline \multicolumn{4}{|c|}{ Main effects } \\
\hline Group & 1.46 & 1 & ns \\
\hline Time & 34.63 & 1 & 0.001 \\
\hline Task & 3.52 & 10 & 0.01 \\
\hline \multicolumn{4}{|c|}{ Interactions } \\
\hline \multicolumn{4}{|c|}{ Group $\times$} \\
\hline Time & 11.54 & 1 & 0.001 \\
\hline \multicolumn{4}{|l|}{ Task $\times$} \\
\hline Time & 3.21 & 10 & 0.01 \\
\hline \multicolumn{4}{|l|}{ Group $\times$} \\
\hline Task & 0.76 & 10 & ns \\
\hline \multicolumn{4}{|l|}{ Group $\times$} \\
\hline Time & & & \\
\hline Task & 0.63 & 10 & ns \\
\hline
\end{tabular}

ns: nonsignificant.

Task $\times$ Time. The significant Time $\times$ Group interaction reflected the greater test-retest increases in WAIS scores by the SI group as compared to the SU group, which was apparent across all three IQ summary measures and the 11 WAIS subtests. The significant Task $\times$ Time interaction points out the greater test-retest increases on the PIQ measure and its subtests relative to the VIQ and its subtests with this pattern holding across both groups.

Tables 3 and 4 provide a comparison of test-retest means for the SU and SI groups for all the WAIS variables along with the results of the Duncan's New Multiple Range Test for these measures. For ease of presentation, the summary IQ measures and the subtests are included in the same table. For the SU group, only the PIQ measure and the OA subtest showed a signifi- 
TABLE 3. Results of statistical comparisons for WAIS test-retest mean scaled-score values for the $S U$ group

\begin{tabular}{|c|c|c|c|c|c|}
\hline \multirow[b]{2}{*}{ WAIS subtests } & \multicolumn{2}{|c|}{ Test scores } & \multicolumn{3}{|c|}{ Retest scores } \\
\hline & Mean & $\mathrm{SD}$ & Mean & SD & Probability \\
\hline VIQ & 90.36 & 16.09 & 89.28 & 14.04 & ns $^{n}$ \\
\hline PIQ & 84.00 & 10.38 & 88.28 & 13.32 & $<0.01$ \\
\hline FSIQ & 86.80 & 13.35 & 88.04 & 13.55 & ns \\
\hline Info & 7.16 & 2.93 & 6.96 & 2.58 & ns \\
\hline Comp & 8.56 & 3.72 & 9.00 & 3.40 & ns \\
\hline Arith & 7.68 & 2.93 & 7.40 & 3.38 & ns \\
\hline Sim & 8.68 & 3.28 & 9.12 & 2.79 & ns \\
\hline Voc & 7.60 & 3.43 & 7.52 & 3.20 & ns \\
\hline DS & 8.08 & 3.21 & 7.88 & 2.03 & ns \\
\hline PC & 8.04 & 2.37 & 8.36 & 2.10 & $\mathrm{~ns}$ \\
\hline PA & 8.00 & 2.87 & 8.68 & 2.80 & ns \\
\hline $\mathrm{BD}$ & 7.72 & 2.59 & 8.40 & 3.22 & ns \\
\hline $\mathrm{OA}$ & 6.76 & 2.14 & 7.88 & 2.42 & $<0.05$ \\
\hline Sym & 7.00 & 2.16 & 7.60 & 3.50 & ns \\
\hline
\end{tabular}

" ns: nonsignificant.

cant increase between test-retest scores (see Table 3). Among the remaining 12 measures, eight improved and four declined but none of these changes were statistically significant. In contrast, the SI group exhibited a significant increase on retest for 11 of the 14 WAIS measures. As shown in Table 4, the VIQ, PIQ, and FSIQ measures improved significantly as as did the Info, Sim, Comp, PC, PA, BD, OA, and Sym subtests. The within-group pattern of greater in- creases in test-retest performance by the SI group is further supported by betweengroup comparisons. Comparisons of the WAIS measures for the SI and SU groups at the time of initial testing indicate that the two groups were not significantly different from each other, except on the Info subtest $(p<0.05)$. On retest, however, nine of the 14 WAIS scores for the SI group, including all three summary IQ scores, were significantly higher $(p<0.01)$ than the retest

TABLE 4. Results of statistical comparisons for WAIS test-retest mean scaled-score values for the SI group

\begin{tabular}{lcccccc}
\hline & \multicolumn{2}{c}{ Test scores } & & \multicolumn{3}{c}{ Retest scores } \\
\cline { 2 - 3 } \cline { 5 - 6 } WAIS subtests & Mean & SD & & Mean & SD & Probability \\
\hline VIQ & 91.96 & 12.51 & & 95.55 & 12.02 & $<0.01$ \\
PIQ & 86.09 & 12.51 & & 96.32 & 16.41 & $<0.01$ \\
FSIQ & 88.78 & 12.12 & & 95.64 & 13.76 & $<0.01$ \\
Info & 8.18 & 2.40 & & 9.21 & 2.53 & $<0.01$ \\
Comp & 8.59 & 3.14 & & 9.59 & 3.06 & $<0.05$ \\
Arith & 7.91 & 3.00 & & 8.82 & 3.02 & ns \\
Sim & 9.45 & 2.63 & & 10.32 & 2.15 & $<0.05$ \\
Voc & 8.00 & 2.74 & & 8.27 & 2.43 & ns \\
DS & 7.91 & 3.15 & & 8.36 & 3.23 & $<0.01$ \\
PC & 8.00 & 2.35 & & 9.41 & 2.89 & $<0.05$ \\
PA & 7.86 & 2.10 & & 9.09 & 2.56 & $<0.01$ \\
BD & 7.59 & 2.74 & & 9.77 & 3.42 & $<0.01$ \\
OA & 7.09 & 2.56 & & 8.77 & 2.96 & $<0.01$ \\
Sym & 7.68 & 3.06 & & 9.73 & 3.86 & $<$ \\
\hline
\end{tabular}

\footnotetext{
a ns: nonsignificant.
} 
scores for the SU group. The subtests that showed a significant difference between the two groups at retest were Info, Arith, Sim, PC, BD, and Sym. Also, VIQ scores were higher than PIQ scores for both groups at the initial testing, a finding that is quite consistent with other studies in the epilepsy literature (Dodrill and Troupin, 1975; Black, 1976). However, at retest there are essentially no differences between the VIQ and PIQ scores for both groups.

Additional information regarding the test-retest WAIS patterns for the SI and SU groups is seen in the analysis of the scores obtained by individual subjects. For this analysis, the chi-square statistic was employed to compare the number of subjects in each group who showed significant test-retest increases or decreases on the WAIS. Table 5 provides a comparison of the distribution of test-retest score changes for the two groups for both the VIQ and PIQ scores using four groupings based on the following arbitrary cutoffs: (a) no change or decrease in performance; (b) a gain of $0-4$ points; (c) a gain of 5-9 points; and (d) a gain of at least 10 points. As can be seen in Table 5, there was a greater tendency for WAIS IQ decreases to occur in the SU group, and for substantial increases (10 points or greater) to occur in the SI group. A chi-square analysis of this difference in pattern of test-retest changes for the SI and SU groups was significant at the $\mathbf{0 . 0 2}$ level $\left(X^{2}=11.29\right)$. The frequency and magnitude of these test-retest changes did not,

TABLE 5. Frequency of test-retest score changes on WAIS VIQ and PIQ for the $S I$ and $S U$ groups

\begin{tabular}{|c|c|c|c|c|c|c|c|c|}
\hline \multirow[b]{2}{*}{ Tests } & \multicolumn{4}{|c|}{ SU group } & \multicolumn{4}{|c|}{ SI group } \\
\hline & $<0$ & $0-4$ & $5-9$ & $\geqslant 10$ & $<0$ & $0-4$ & $5-9$ & $\geqslant 10$ \\
\hline VIQ & $14^{n}$ & 4 & 6 & 1 & 3 & 10 & 7 & 2 \\
\hline PIQ & 7 & 8 & 4 & 6 & 3 & 1 & 5 & 13 \\
\hline
\end{tabular}

${ }^{a}$ The numbers in this table represent instances of change at the various levels of scores. Each subject in the study $(N=47)$ contributes two scores in the table matrix, a viq and piq test-retest change score, yielding a total of 94 instances. however, occur with equal likelihood for the VIQ and PIQ measures. Rather, PIQ scores were more likely to increase, while VIQ scores tended to show decreases or minimal increases $\left(X^{2}=15.22, p<0.01\right)$.

\section{DISCUSSION}

A number of conclusions regarding intellectual deterioration in epilepsy can be drawn from these results. First, changes in seizure frequency are associated with direction and magnitude of changes on WAIS test-retest scores. While those persons whose seizure frequency decreased (SI group) showed general test-retest improvements on the WAIS, this was not true for the group of patients whose seizures did not improve (Tables 3 and 4). Second, testretest improvements occurred more frequently on the WAIS Performance measures than on the WAIS Verbal measures.

The first finding stands in contrast to the test-retest findings of a number of earlier investigations (Fox, 1924; Patterson and Fonner, 1928; Fetterman and Barnes, 1934). The present study, however, avoided some of the major methodological problems associated with these earlier studies. Among them are, wide variability of patient age range and test-retest interval, wide distribution of initial IQ levels, and use of institutionalized patients. Therefore, in the present study it was possible to examine the relationship between seizure frequency and test-retest performance of intellectual functioning in a less ambiguous fashion.

In the SI group, the improvement in level of intellectual functioning was apparent almost across the full range of skills and abilities tapped by the WAIS. There was a pattern, however, of relatively greater test-retest improvements on the Performance measures as compared to the Verbal measures, while decreases or minimal increases were more likely to be found on the Verbal measures. Both the overall group analyses (Tables 3 and 4), and the individual subject analyses (Table 5 ), indicated 
that the Performance measures changed more frequently, more often in a positive direction, and to a greater extent than did the Verbal measures. While this finding is in conflict with Rodin's (1968) results, they do agree with the findings of a number of other investigators. The relatively greater fluctuation of WAIS Performance measures has been reported for both normal populations (Kangas and Bradway, 1971; Catron, 1978; and Catron and Thompson, 1979), as well as for various brain-damaged populations (Ladd, 1964; Duke et al., 1968; Mandleberg and Brooks, 1975; and Dodrill and Troupin, 1975). Mandleberg and Brooks (1975) suggest that the greater fluctuation observed on the WAIS Performance measures is due to their relatively greater complexity in comparison to the Verbal measures. Another possible explanation can be found in the different nature of the problem-solving demands (new learning versus old learning) inherent in WAIS Performance as opposed to Verbal measures. Hebb (1949) postulated that it is new learning situations that are more vulnerable to the effects of brain damage. Also, since scores on the Performance measures are determined by how quickly the correct responses are provided, they may be influenced more by such variables as mental alertness, physical state, motivation, anxiety, and other affectual states. Whatever the reason, it is clear from the results of the present study that WAIS Performance measures are more likely to change than Verbal measures, with improvements occurring more often in the SI group.

An often cited explanation for the fluctuation in WAIS test-retest scores in both normal and brain-damaged groups is practice effect (Matarazzo, 1972; Matarazzo et al., 1973). It is unlikely, however, that the present results are due simply to practice. Since the SI and SU groups started out with essentially the same initial performance levels on the WAIS, one would expect the two groups to be equivalent in their potential to reflect the effects of practice. Yet, the test-retest improvements which were found are not equivalent for the two groups. Rather, the SI group improved their scores to a greater extent than did the SU group (Tables 3 and 4). In addition, half of the subjects from the SI group demonstrated test-retest improvements of 10 points or more, which is double the improvement typically expected simply from practice effects (Matarazzo, 1972).

The test-retest results of the SU group warrant additional comment. While this group showed little improvement, there also appeared to be little evidence of pronounced deterioration in their performance. However, when one goes from an examination of the group data as a whole to an analysis of the individual patients (Table 5), it becomes evident that a substantial number of the SU patients did, in fact, score lower on retest. It should also be noted that the retest interval used in the present study was shorter and less variable than that used in many of the earlier epilepsy studies. Additional serial testing and continuous monitoring of patient clinical status are necessary to determine the degree and type of longer term intellectual-cognitive changes that are associated with improvement or lack of improvement in seizure frequency.

In the present study, change in seizure frequency was the sole criterion used to determine change in clinical status of the epilepsy patients. Clearly, there are other clinical seizure variables that may be related to test-retest patterns of performance. Seizure type, severity, and presence and type of EEG abnormalities are a few such variables. A person, for example, can continue to have a high number of seizures while the severity of the attacks can change (e.g., length of time, degree of postictal confusion). Laterality of EEG abnormality may also be a significant variable, as was recently suggest in a paper by Berent et al. (1980). Using a cross-sectional design, they found that epilepsy patients with lateralized left hemisphere EEG abnormalities tended 
to show greater decrement with age in their performance on several cognitive measures as compared to right hemisphere lateralized patients. Obviously, more studies are needed to provide a coherent framework for predicting which epilepsy patients will or will not improve in intellectual functioning over time. The present study does show that change in seizure frequency is a variable that plays an important role in determining changes in intellectual functioning.

\section{ACKNOWLEDGMENTS}

Preparation of this article and supporting research were funded in part by the $\mathrm{Na}$ tional Institute of Neurological and Communicative Disorders and Stroke Contracts: NO1-NS-5-2329, Bio-PsychoSocial Aspects of Epilepsy, Dr. Thomas Boll, and NO1-NS-7-2373, Perceptual Studies in Epilepsy, Dr. Stanley Berent. The authors would like to acknowledge the assistance of Patrick C. Fowler during the course of manuscript preparation and Bruno Giordani for his work on the data management system. The research presented in this paper was conducted at the Highlands Center, Comprehensive Epilepsy Program, University of Virginia Medical Center.

\section{REFERENCES}

Arieff AJ and Yacorzynski GK. Deterioration of patients with organic epilepsy. J Nerv Ment Dis 26:49-55, 1942.

Berent S, Boll TJ, and Giordani B. Hemispheric site of epileptogenic focus: Cognitive, perceptual, and psychosocial implications for children and adults. In: Proceedings of the Epilepsy International Symposium. Raven Press, New York, 1980.

Black FW. Cognitive, academic, and behavioral findings in children with suspected and documented neurological dysfunction. J Learn Disabil 9:55-60, 1976.

Catron DW. Immediate test-retest changes in WAIS scores among college males. Psychol Rep 43:279-290, 1978 .

Catron DW and Thompson CC. Test-retest gains in WAIS scores after four retest intervals. $J$ Clin Psychol 35:352-357, 1979.

Chaudhry MR and Pond DA. Mental deterioration in epileptic children. J Neurol Psych 24:213, 1961.

Collins AL. Psychometric records of institutionalized epileptics. J Psychol 2:359-370, 1941.
Dawson $S$ and Conn JCM. Intelligence of epileptic children. Arch Dis Child 4:142-151, 1929.

Dodrill CB and Troupin AS. Effects of repeated administrations of a comprehensive neuropsychological battery among chronic epileptics. $J$ Nerv Ment Dis 161:185-190, 1975.

Duke RB, Bloor BM, Nugent R, and Mazjoub HS. Changes in performance on WAIS, trail making test, and finger tapping test associated with carotid artery surgery. Percept Mot Skills 26:399-404, 1968.

Fetterman J and Barnes M. Serial studies of the intelligence of patients with epilepsy. Arch Neurol Psych 32:797-801, 1934.

Folsom A. Psychological testing in epilepsy: cognitive function. Epilepsia 2:15-22, 1953.

Fox JT. Response of epileptic children to mental and educational tests. $B r J M e d$ Psychol 4:235-258, 1924.

Gastaut H. Clinical and electroencephalographic classification of epileptic seizures. Epilepsia 11:102$114,1970$.

Hebb DO. The Organization of Behavior. John Wiley and Sons, New York, 1949.

$\mathrm{K}$ angas $\mathrm{J}$ and Bradway $\mathrm{K}$. Intelligence at middle age: A thirty-eight year follow-up. Dev Psych 5:333-337, 1971.

Kramer CY. Extension of multiple range tests to group means with unequal numbers of replications. Biometrics 12:307-310, 1956.

Ladd CE. WAIS performance of brain damaged and neurotic patients. J Clin Psychol 20:114-117, 1964.

Mandleberg IA and Brooks DN. Cognitive recovery after severe head injury: 1. Serial testing on Wechsler Adult Intelligence Scale. J Neurol Neurosurg Psychiatry 38:1121-1126, 1975.

Matarazzo JD. Wechsler's Measurement and Appraisal of Adult Intelligence, 5 ed. Oxford University Press, New York, 1972.

Matarazzo RG, Wiens AN, Matarazzo JD, and Manaugh TS. Test-retest reliability of the WAIS in a normal population. J Clin Psychol 29:194-197, 1973.

Myers JK and Bean LL. A Decade Later: A Followup of Social Class and Mental Illness. John Wiley and Sons, New York, 1968.

Paskind HA. Extramural patients with epilepsy with special reference to the frequent absence of deterioration. Arch Neurol Psych 28:370-385, 1932.

Patterson HA and Fonner D. Some observations on the intelligence quotient in epileptics. Psychiatry $Q$ 2:542-548, 1928.

Rodin EA. The Prognosis of Patients with Epilepsy. CC Thomas, Springfield, III, 1968.

Sullivan EB and Gahagan L. Intelligence of epileptic children. Genet Psychol Monogr 17:309-376, 1935.

Tarter RE. Intellectual and adaptive functioning in epilepsy: A review of 50 years of research. Dis Nerv Syst 33:763-770, 1972.

Tenny JW. Epileptic children in Detroit's special school program, a study. Except Child 21:162, 1955.

Yacorzynski GK and Arieff AJ. Absence of deteriora- 
tion in patients with non-organic epilepsy with special reference to bromide therapy. J Nerv Ment Dis 95:687-697, 1942.

\section{RÉSUMÉ}

Les résultats obtenus à l’échelle de WAIS (Wechsler Adults Intelligence Scale) à partir d'une passation I (test) et d'une passation II (retest) chez deux groupes d'épileptiques adultes sont présentés et comparés: (a) Dans un groupe la fréquence des crises a diminué durant l'intervalle "test-retest" (c'est à dire dans l'intervalle séparant la passation I (test) de la passation II (retest): Groupe des crises améliorées (SI: seizures improved). (b) Dans l'autre groupe le nombre des crises au contraire a augmenté ou bien est resté identique au cours de l'intervalle "test-retest": Groupe des crises non améliorées (SU: seizures unimproved). Le groupe des "crises améliorées" montre une amélioration significative tant sur le plan du QIV (quotient de l'échelle verbale), que du QIP (quotient de l'échelle performance) et du QIG (quotient global), ainsi que de 8 des subtests parmi les onze que contien l'échelle. En comparaison le groupe des "crises non améliorées" ne montre une amélioration significative qu'au niveau du QIP et en particulier sur le subtest d'assemblage d'objets (celui-ci faisant partie de l'échelle performance). De plus, on observe entre les deux groupes des différences du "type" des modifications entraînées par la situation "test-retest", sur les résultats obtenus à l'échelle performance et ceux obtensus à l'échelle verbale. Ces résultats permettent de suggérer que, dans le fonctionnement intellectuel des sujets épileptiques, les changements dans la fréquence des crises sont un des facteurs à mettre en corrélation avec les changements observés à partir de la situation "test-retest".

\section{(J. L. Gastault, Marseilles)}

\section{RESUMEN}

Se compararon dos grupos de adultos con epilepsia por medio del rendimiento en dos tests de WAIS. En un grupo, la frecuencia de los ataques había disminuido en el intervalo entre el primer test y el segundo [grupo con mejoria (SI)], mientras que en el otro el número de crisis no había variado o había aumentado [grupo sin mejoria (SU)]. El grupo SI mostró una mejoría en la escala verbal $\mathrm{CI}$, en la realización $\mathrm{CI}$, en la escala total de CI y en los subtests WAIS. En comparación, el grupo SU sólo mostró un aumento significativo en la realización $\mathrm{Cl}$ y en el subtest de Reunión de Objetos. Además, se observaron diferencias entre los dos grupos en lo que respecta a la primera y a la segunda prueba en la realización de las medidas verbales. Los resultados sugieren que los cambios en la frecuencia de los ataques juegan un papel en lo que respecta a función intelectual cuando se compara el primer WAIS con el segundo.

(A. Portera Sanchez, Madrid)

\section{ZUSAMMENFASSUNG}

Test und Retest Ergebnisse im WAIS von 2 Gruppen erwachsener Epileptiker werden dargestellt und verglichen. In einer Gruppe hatte die Anfallshäufigkeit während des Test-Retest-Intervalls abgenommenverbesserte Gruppe (SI)_und in einer anderen Gruppe war die Anfallshäufigkeit entweder gestiegen oder gleich geblieben während des Test-Retest-Intervallsunveränderte Gruppe (SU). Die SI-Gruppe zeigte signifikante Verbesserung zwischen Test und Retest im Verbal-IQ des WAIS, im Handlungsteil und im Gesamt-IQ ebenso wie in 8 von 11 WAIS Subtests. Im Vergleich hierzu zeigte die SU-Gruppe signifikante Verbesserung nur im Handlungs-IQ und im Objektezuordnungs-Subtest. Weiterhin wurden Unterschiede zwischen den beiden Gruppen im Muster der TestRetest-Veränderungen im Verhältnis des Handlungsteils zum Verbalteil bemerkt. Die Ergebnisse lassen vermuten, da13 die Veränderung der Anfallshäufigkeit einer der Faktoren ist, der hinsichtlich der intellektuellen Funktion anfallskranker Patienten Beziehungen zu den Veränderungen des Test-Retest-Ergebnis aufweist.

(D. Scheffner, Heidelherg) 